\title{
Pricing Decisions in Closed-Loop Supply Chains with Competitive Fairness-Concerned Collectors
}

\author{
Yadong Shu $\mathbb{D}^{1,2}$ Ying Dai $\mathbb{D}^{1},{ }^{1}$ and Zujun Ma $\mathbb{D}^{1,3}$ \\ ${ }^{1}$ Institute for Logistics and Emergency Management, School of Economics and Management, Southwest Jiaotong University, \\ Chengdu 610031, China \\ ${ }^{2}$ School of Mathematics and Statistics, Guizhou University of Finance and Economics, Guiyang 550025, China \\ ${ }^{3}$ Logistics and E-commerce College, Zhejiang Wanli University, Ningbo 315100, China \\ Correspondence should be addressed to Ying Dai; ydai@swjtu.edu.cn
}

Received 10 May 2020; Revised 23 September 2020; Accepted 18 October 2020; Published 17 November 2020

Academic Editor: Xander Wang

Copyright (c) 2020 Yadong Shu et al. This is an open access article distributed under the Creative Commons Attribution License, which permits unrestricted use, distribution, and reproduction in any medium, provided the original work is properly cited.

\begin{abstract}
Based on the Shapley value fairness concern framework, a fairness concern utility system is established for the closed-loop supply chain (CLSC) with one manufacturer, one retailer, and two competitive collectors. Under the five models (one centralized and four decentralized), the influence of competitive strength and fairness concern degree of collectors on the pricing decisions is analyzed. The following conclusions can be obtained: (1) When the manufacturer considers the fairness concern of the collectors, fairness concern is a way for the collectors to obtain more profit. Whether the manufacturer "proactively" considers the fairness concern of the collectors is an approach to benefiting the collectors but only in the case of "active" consideration, there is less selfloss to the manufacturer. (2) When the collectors' fairness concern cannot be considered by the manufacturer, the equilibrium recycling price sets lower for the purpose of achieving more profit by the collectors. At this point, the profit of the collectors and the manufacturer is the lowest, and so is the return rate of the CLSC. (3) When the collectors do not care about whether they are being fairly treated but the manufacturer "actively" takes the fairness of the collectors into consideration, the collectors get "unexpected" attention from the manufacturer, which makes the performance of the collectors more positive than it is when their fairness concerns are taken into account. The profit increased by the collectors is more than that lost by the manufacturer, so the profit of the CLSC is the largest. Additionally, our findings provide some managerial insights on the pricing decision in the case where the collectors consider fairness concern.
\end{abstract}

\section{Introduction}

With the exhaustion of resources and the intensification of environmental pollution, increasing people are aware of the importance of the effective collecting and reuse of used products. On the one hand, the government has promulgated a series of environmental protection laws, requiring enterprises to collect and recycle at least a certain proportion of the collecting of used products [1-3]. On the other hand, many enterprises have been conscious of the important role played in collecting used products in sustainable development, which can not only reduce environmental pollution and enhance enterprises' social reputation but also reduce production costs so that competitiveness is enhanced [4-6].
In order to make full play to their advantages, the manufacturer tends to outsource the recycling of waste products to the collectors who are specialized in recycling activities. The manufacturer focuses on the production of new products and the remanufacturing of waste products [7-9]. Both of the manufacturer and the collectors make a profit from reverse recycling activities. For example, in China, only the waste paper recycling business profit reached $\$ 5.72$ billion in 2017. Hence, there exists inevitable competition among multiple collectors in the process of collecting used products. How does the competition among the collectors affect the pricing decision in the CLSC? If the collection activity is profitable, such an appealing activity consequentially brings competitions. To whom is it 
beneficial? Does it jeopardize the benefit of the members in the CLSC?

Additionally, the decision-makers are also interested in the fairness of the income distribution while pursuing the maximization of personal interests. For instance, Scheer et al. [10] also surveyed 417 car dealers in the United States and 289 auto dealers in Holland and found that they should pay more attention to the fairness of distribution when they trade with business partners. Subsequent research has also documented cases where both of the manufacturer and the retailers sacrifice their own margins for the benefit of their counterpart because of fairness concern [11-14].

It is worth noting that the existing research on fairness concern of CLSC considers the fairness concern of the manufacturer or the retailer but barely considers that of the collectors [15]. With the pressure of environmental regulations, increased consumers' awareness of environmental protection, and the profitability of collection activities, the collection of used products has become an indispensable link in CLSC management. More and more collectors engaging in the recycling of used products have stepped onto the stage of history and played an irreplaceable role.

To investigate the influence of fairness concern of collectors on CLSC decisions, this paper concentrates on a CLSC composed of one manufacturer, one retailer, and two collectors. Based on observations from current practice and the extant literature, five models are considered: (1) the centralized decision-making model C; (2) the model FY in which collectors are fairness-concerned and the manufacturer "passively" considers the fairness concern of collectors; (3) the model FN in which collectors are fairness-concerned but the manufacturer neglects the fairness concern of collectors; (4) the model NN in which collectors are not fairness-concerned and the manufacturer does not consider the fairness concern of collectors; (5) the model NY in which collectors are not fairness-concerned but the manufacturer "proactively" considers the fairness concern of collectors.

More specifically, this paper aims to analyze the following issues:

(1) The equilibrium solution in the CLSC in the five models

(2) The influence of fairness concern coefficient and competition intensity of the collectors on equilibrium solution in the CLSC

(3) How to design incentive contracts to make the utility of decision-makers in the CLSC system realize Pareto improvement (see [16])

The main contributions of this paper are structured as follows. First, considering the impact of fairness concern of collectors on CLSC decision-making under multiple models, it is a supplement to existing research. Second, the decisionmaking is discussed when collectors are fairness-neutral but the manufacturer "actively" considers fairness concern of collectors. Third, in addition to considering the impact of fairness concern on decision-making in the CLSC, this paper also considers the impact of the competitive intensity of collectors on decision-making in the CLSC.
In a deeper sense, our work has enriched the research results that consider the factors of the decision-makers' behavior in the CLSC. The remaining parts of the paper are organized as follows: the next part introduces the relative literature review. The third part lists problem description and model hypotheses. The fourth part studies the optimal decision-making of the CLSC. The incentive contracts are given in the fifth part. And the last part provides the numerical analysis and the conclusions.

\section{Literature Review}

The paper discusses the change of equilibrium solution of the system considering the collectors' fairness concern under the five models. In general, the research work of the paper is based on a vast body of references.

The first part of the literature is related to pricing decision. Heydari et al. [17] addressed the problem of optimal decision-making for a three-tier dual-channel green supply chain. Esmaeili et al. [18] studied short-term and long-term pricing decisions of a closed-loop supply chain using Stackelberg game and evolutionary game theory, respectively. Ma et al. [19] showed the pricing decisions of closedloop supply chain under four reverse channels when retailers consider marketing efforts. Diabat and Jebali [20] considered the network design of a closed-loop supply chain for consumer durables under recycling legislation and analyzed the influence of model parameters on pricing decisions. The study by Huang et al. [8] provided a reference for choosing single or dual recycling channels for recycling used products. Wen et al. [21] analyzed the impact of retailers' pricing strategies on the closed-loop supply chain under the consideration of consumer environmental responsibility; equal pricing is a win-win strategy when the acceptance of the remanufactured product reaches a certain threshold. Jalali et al. [22] believed that the presence of complementary products increases the difficulty in decision-making. Meng et al. [23] suggested that the government should not always provide consumption subsidies, because the consumption subsidies undermined the demand for new products while promoting the demand for remanufactured products. The research of Wang et al. [24] showed that the choice of recycling channels depends on the unit cost of self-recycling and the compensation of outsourcing recycling. However, the above research does not continue to discuss the influence of competitive factors on decision-making. Giri et al. [25] discussed the decision problem of retailer's competition under the same and the different wholesale prices. Savaskan and Wassenhove [26] discussed the design of the reverse channel under the competition of the retailer. Ferguson et al. [27] analyzed the impact of competition on recycling strategies. The research by Lee and Sana [28] showed that as price competition intensifies between collectors, the profitability of the supply chain decreases. Xing et al. [29] found that the degree of competition among recyclers changes in the opposite direction to the expected utility of manufacturers. The studies above show that the competitive factors play a pivotal role in the decision-making process of the supply chain. 
The second part of the literature is related to fairness concern. Ho and Zhang [30] confirmed the existence of fairness concern in the supply chain through experiments. Zhang et al. [31] believed that the retailer's fairness concern would cause the loss of supply chain. Li et al. [32] found through theoretical research that the retailer's fairness concern is beneficial to supply chain decision-making. Huang [33] believed that different types of fairness concern of retailers have different effects on CLSC pricing decisions. Zhang et al. [34] believed that when the retailer's fairness concern is at a high level, it is not good for the manufacturer. Therefore, the manufacturer will not adopt green manufacturing strategy. The aforementioned studies were carried out from the perspective of retailers' fairness concern. Some researchers have expanded the scope of their research. For example, Li et al. [35] revealed that the impact of the manufacturer's fairness concern on supply chain decisions is related to the market share of retailers. Zhen et al. [36] believed that fairness concern from both of the manufacturer and the retailer may bring more profit to the supply chain when the retailer has multichannel. Huang et al. [9] believed that when the collector had fairness concern, the manufacturer should set higher transfer payments to encourage the collector to participate in recycling activities.

These studies present that fairness concern will affect supply chain decisions. However, these studies ignore the power and contribution of the players. Chen et al. [13] and Shu et al. [37] used the Nash bargaining solution as a fairness reference point to study the influence of fairness concern on supply chain decision-making. However, the Shapley fairness distribution principle is the best way when the alliance has more than two members, which emphasizes that the members of the alliance are allocated according to the size of their contributions [38]. Therefore, as a result of fairness reference, Shapley value naturally becomes a fairness reference point for building a fairness concern utility system. Unlike the studies above, this paper introduces the impact of fairness concern on decision-making while considering competition in the CLSC.

The third part of the literature is concerned with coordination. It is well known that in most cases the wholesale price contract cannot achieve a coordination of the supply chain. However, in reality, it is easy to perform and the supervision cost is low, so wholesale price contracts become favored by a large number of practitioners. Cui et al. [11] found that, in the linear demand condition when the fairness concern of the members was considered, only setting a higher wholesale price than the cost can achieve both the coordination of the supply chain and the Pareto improvement of the system. The same conclusion was acquired in the nonlinear demand condition by the authors in [39], who found that the supplier could offer wholesale price contracts to achieve the coordination of the supply chain only if one member of the supply chain had fairness concern. Du [40] proved that a fairness preference could change the equilibrium solutions, and in certain conditions, the wholesale price contracts could achieve the competitive coordination of the supply chain. When the fairness concern information is asymmetrical, through a mass of experimental data by Katok et al., [41] showed that the fairness concern behaviors of the supply chain members had a great influence on the formation of contracts to achieve coordination. Other commonly used contracts also enable supply chain to achieve coordination. Karakostas at al. [42] suggested that a large majority of experimental subjects choose the revenuesharing contract. This choice not only turns out to be the most efficient but at the same time is fair. Heydar et al. [43] realized the coordination of two-stage reverse supply chain through revenue-sharing contract. Monda and Giri [44] have shown that cost-sharing contracts could coordinate the two-cycle closed-loop green supply chain, and the performance of the supply chain can be improved through green innovation or marketing. The research of $\mathrm{Li}$ et al. [45] showed that the simple transfer payment contract coordination of the supply chain failed when the collectors had multiple fairness concerns. Zhang and Ren [46] achieved perfect coordination of CLSC by revenue-sharing and the two-part Tariff contract, and the influence of coordination parameters on optimal supply chain performance was also discussed. Wang et al. [47] also reached a similar conclusion in the CLSC with dual-collecting and the two-part Tariff contract works better. Based on the previous literature, the paper attempts to apply the two-part Tariff contract mechanism for achieving a Pareto improvement in a CLSC.

To sum up, the existing literature on the fairness concern of the supply chain has focused on whether the fairness concern is symmetrical or asymmetric and when one party hopes to be treated fairly, whether the other considers this fairness. There is no literature about the case where one party does not consider the fairness of profit distribution, while the other party "actively" considers that the other is fairnessconcerned. To address this gap, the Stackelberg game is applied to analyze the competition between collectors under five models and study the impact of fairness concern in the CLSC on pricing decisions. The results suggest that as long as the manufacturer considers the fairness concern of the collectors, the profit of the collectors will increase, which is a profit-giving behavior. However, when the collectors' fairness concern cannot be considered by the manufacturer, the equilibrium recycling price is set lower for the purpose of achieving more profit by the collectors, and the efficiency of the CLSC is the lowest. We present some research results to highlight the contributions of this paper (see Table 1).

\section{Problem Description and Model Assumptions}

3.1. Problem Description. In order to discuss the impact of fairness concern of collectors on pricing decisions and coordination, this paper considers a CLSC system consisting of a manufacturer, a retailer, and two homogeneous collectors. The closed-loop supply chain system and the symbols involved are illustrated in Figure 1 and Table 2.

Throughout the entire CLSC, the manufacturer outsources the used product recycling business to dedicated collectors. The collectors collect the used products from the market at a certain price and transfer them to the 
TABle 1: The literature positioning of this paper.

\begin{tabular}{lccc}
\hline Research & $\begin{array}{c}\text { Considering the } \\
\text { competition factors }\end{array}$ & $\begin{array}{c}\text { Followers are fairness-concerned, } \\
\text { and leaders consider the fairness } \\
\text { concern of followers }\end{array}$ & $\begin{array}{c}\text { Followers are unfairness-concerned, and } \\
\text { leaders consider the fairness } \\
\text { concern of followers }\end{array}$ \\
\hline Heydari et al. [17] & $\times$ & $\times$ & $\times$ \\
Ma et al. [19] & $\times$ & $\sqrt{ }$ & $\times$ \\
Wen et al. [21] & $\times$ & $\times$ & $\times$ \\
Giri and Sharma [25] & $\sqrt{ }$ & $\times$ & $\times$ \\
Savaskan and Wassenhove [26] & $\times$ & $\sqrt{ }$ & $\times$ \\
Ho and Zhang [30] & $\times$ & $\sqrt{ }$ & $\times$ \\
Xiao et al. [32] & $\times$ & $\sqrt{ }$ & $\times$ \\
Shu et al. [37] & $\times$ & $\sqrt{ }$ & $\sqrt{ }$ \\
This paper & $\sqrt{ }$ & & $\times$ \\
\hline
\end{tabular}

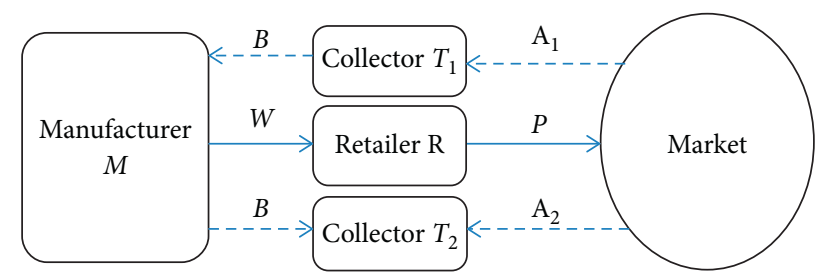

Figure 1: The closed-loop supply chain configuration.

TABle 2: Symbol description.

\begin{tabular}{|c|c|}
\hline \multicolumn{2}{|l|}{ Parameters } \\
\hline M & Manufacturer \\
\hline$R$ & Retailer \\
\hline$T_{i}$ & Collector $i, i=1,2$ \\
\hline$A$ & The potential capacity of the market \\
\hline$B$ & The sensitivity coefficient of the price \\
\hline$H$ & Quantity of used products that the collector pays no collecting cost \\
\hline$C$ & The cost of the new products produced by raw materials \\
\hline$C_{r}$ & The cost of remanufacture made by collecting used products \\
\hline$\Delta$ & The per unit saving cost from collecting to remanufacturing, $\Delta=c-c_{r}$ \\
\hline$\Delta$ & The substitution coefficient of the competition between the collectors, and $0<\delta<1$ \\
\hline$D(p)$ & The retailer's market demand \\
\hline$G_{i}$ & Collection amount of the collector $i, G=G_{1}+G_{2}$ \\
\hline$r_{\mathrm{sc}}$ & Collecting rate of the CLSC, and $r_{\mathrm{sc}}=G / D$, and $0<r_{\mathrm{sc}}<1$ \\
\hline$C$ & The centralized decision-making model \\
\hline TY & The collectors are fairness-concerned and the manufacturer considers (passive) fairness concern of the collectors \\
\hline $\mathrm{TN}$ & The collectors are fairness-concerned but the manufacturer does not consider fairness concern of the collectors \\
\hline NN & The collectors are not fairness-concerned and the manufacturer does not consider fairness concern of the collectors \\
\hline NY & The collectors are not fairness-concerned but the manufacturer considers (active) fairness concern of the collectors \\
\hline Subscript sc & The CLSC decision \\
\hline Superscript “*” & The optimal solution of the CLSC \\
\hline$\lambda$ & Fairness concern coefficient of the collectors \\
\hline$\varphi T_{i}$ & Fairness reference point of the collectors i \\
\hline \multicolumn{2}{|l|}{ Decision variables } \\
\hline$p$ & Retail price set by the retailer \\
\hline$A_{i}$ & Recycling price set by the collector \\
\hline$B$ & Transfer price set by the manufacturer, $A_{i}<B<\Delta$ \\
\hline$W$ & Wholesale price set by the manufacturer \\
\hline \multicolumn{2}{|c|}{ Performance measures } \\
\hline$\pi_{M}^{l}$ & The profit of the manufacturer under the model $l, l \in\{\mathrm{FY}, \mathrm{FN}, \mathrm{NY}, \mathrm{NN}\}$ \\
\hline$\pi_{R}^{l_{1}^{M}}$ & The profit of the retailer under the model $l, l \in\{\mathrm{FY}, \mathrm{FN}, \mathrm{NY}, \mathrm{NN}\}$ \\
\hline$\pi_{T_{i}}^{l}$ & The profit of the collector $T_{i}$ under the model $l, l \in\{\mathrm{FY}, \mathrm{FN}, \mathrm{NY}, \mathrm{NN}\}$ \\
\hline$\pi_{\mathrm{sc}}^{l^{i}}$ & The profit of the CLSC under the model $l, l \in\{\mathrm{FY}, \mathrm{FN}, \mathrm{NY}, \mathrm{NN}\}$ \\
\hline$u_{T_{i}}^{l}$ & The utility of the collector $T_{i}$ under the model $l, l \in\{\mathrm{FY}, \mathrm{FN}, \mathrm{NY}, \mathrm{NN}\}$ \\
\hline
\end{tabular}


manufacturer at an appropriate price. The manufacturer processes the used products. After processing (such as repairs, remanufacturing, recycling materials, etc.), new products and remanufactured products are wholesaled to the retailer, who sells the new products and remanufactured products on the market. What needs to be pointed out is because this paper is a scientific research activity carried out in the context of improving recycling channels, increasing the return rate of used products, promoting sustainable development of society, and then improving people's quality of life, the focus is on reverse recycling channels. Since the retailer does not pay attention to the fairness of profit distribution but only his own income, the retailer is fairnessneutral.

3.2. Model Assumptions. On the premise of not affecting the main conclusions of this paper, the complex supply chain in reality is made a proper simplifying assumption.

Assumptions 1. The marketing demand $D(p) .(D(p) \geq 0)$ is a deterministic decreasing function of $p$, expressed as

$$
D(p)=a-b p .
$$

Assumptions 2. Following Savaskan and Van Wassenhove [26] and Xing et al. [29], the collection amount is determined by the recycling price of the two collectors, and in the collection process, the two collectors form a competitive relationship, that is,

$$
G_{i}=h+A_{i}-\delta A_{j}, \quad(i=1,2 ; j=3-i) .
$$

Here, $\delta$ denotes quantity of used products that is gained in the case that the collector pays no collecting cost, and $0<\delta<1$ indicates that the collection amount is more sensitive to its own recycling price.

Assumptions 3. No waste will occur in the process of recycling and remanufacturing the used products; that is, the conversion rate of the used products into new products is 1 , and the new products and remanufactured products are homogeneous.

Assumptions 4. The new products and the remanufactured products are completely replaceable, and the retail price in the market is the same; that is, the products produced using the new materials and the remanufactured products are homogeneous ones and are sold in the market at the same price.

Assumptions 5. Members of the closed-loop supply chain play a Stackelberg master-slave game with the manufacturer as the leader and the retailer and the collector as followers. The manufacturer and the retailer are fairness-neutral and seek to maximize profits. When the collector is fairnessneutral, he seeks to maximize profit. When fairness attention is paid, he seeks to maximize utility.
Assumptions 6. The information among the manufacturer, the retailer, and the collectors is symmetrical; that is, they understand each other's costs, pricing strategies, and response functions.

From the assumptions and descriptions above, the objective functions of the manufacturer $M$, the retailer $R$, and the collector $T_{i}$ are as follows:

$$
\left\{\begin{array}{l}
\max _{B, w} \pi_{M}=(w-c) D+\sum_{i=1}^{2}(\Delta-B) G_{i}, \\
\max _{p} \pi_{R}=(p-w) D \\
\max _{A_{i}} \pi_{T_{i}}=\left(B-A_{i}\right) G_{i} .
\end{array}\right.
$$

\section{Problem Description and Model Assumptions}

4.1. Construction of Shapley Reference Framework. The retailer, as a single decision-maker, ignores fairness of the alliance. With regard to an individual who has the tendency to fairness concern behavior, his utility is connected with actual profit and difference of fairness reference point. The background considered in paper is a convex game; as a result, Shapley value can be employed to describe equitable distribution. It emphasizes the distribution according to the ability and the contribution of the system members, and he pursues the relative fairness between the members instead of absolute fairness.

The system includes one manufacturer $M$ and two collectors $T_{1}$ and $T_{2}$, and the recycling prices of the two collectors are, respectively, $A_{1}$ and $A_{2}$. The Shapley value distributions of all the members are $\left\{\varphi_{M}(v), \varphi_{T_{1}}(v), \varphi_{T_{2}}(v)\right\}$. It can be imagined that the Shapley value is a function of $A_{1}$ and $A_{2}$. The system profit changes with the variation of $A_{1}$ and $A_{2}$, and then the gross profit changes, accordingly, and so does the Shapley value. Next, we, respectively, calculate the system eigenvalue, namely, the profits of the system, all of which are zero in one-member system; namely, $v(M)=0$, $v\left(T_{1}\right)=0$, and $v\left(T_{2}\right)=0$. Here, it only considers the remanufacturing profit created by the manufacturer. In the two-member system, when the two collectors coexist simultaneously, the profit is zero; that is, $v\left(T_{1}, T_{2}\right)=0$. When there is only one manufacturer and one collector, the profit of the system can be presented as

$$
v\left(M, T_{i}\right)=\left(\Delta-A_{i}\right) G_{i}^{\prime} .
$$

At this time, there is no competition between the collectors, so the collecting quantity is

$$
G_{i}^{\prime}=h+A_{i}
$$

When the system members are the collector and the manufacturer, the system profit is as follows:

$$
v\left(M, T_{i}, T_{j}\right)=\left(\Delta-A_{i}\right) G_{i}+\left(\Delta-A_{j}\right) G_{j} .
$$

It should be noted that the recycling price Ai differs in the cases of single and multiple collectors. Applying the 
Shapley three principles of fairness (see [48, 49]), we calculate the fairness distribution of the manufacturer and the collectors as follows:

$$
\left\{\begin{array}{l}
\varphi_{M}(v)=\left(\Delta-A_{i}\right)\left(\frac{1}{2} h+\frac{1}{2} A_{i}-\frac{1}{3} \delta A_{j}\right)+\left(\Delta-A_{j}\right)\left(\frac{1}{2} h+\frac{1}{2} A_{j}-\frac{1}{3} \delta A_{i}\right) \\
\varphi T_{i}(v)=\frac{1}{2}\left(\Delta-A_{i}\right)\left(h+A_{i}\right)-\frac{1}{3} \delta \Delta\left(A_{i}+A_{j}\right)+\frac{2}{3} \delta A_{i} A_{j} \\
\varphi T_{j}(v)=\frac{1}{2}\left(\Delta-A_{j}\right)\left(h+A_{j}\right)-\frac{1}{3} \delta \Delta\left(A_{j}+A_{j}\right)+\frac{2}{3} \delta A_{i} A_{j},
\end{array}\right.
$$

according to

$$
\begin{gathered}
\frac{\partial^{2} \varphi M}{\partial A_{i}^{2}}=-1<0, \\
\frac{\partial^{2} \varphi T_{i}}{\partial A_{i}^{2}}=-1<0 .
\end{gathered}
$$

The fairness distribution of the two collectors $T_{1}$ and $T_{2}$ is a concave function concerned with their own recycling price, so there exists the optimal recycling price which makes the Shapley maximum.

Thus, the utility function of collectors concerned with fairness concerns is

$$
u_{T_{i}}^{l}=\pi_{T_{i}}^{l}+\lambda\left(\pi_{T_{i}}^{l}-\varphi T_{i}\right) .
$$

Here, $l \in\{\mathrm{FY}, \mathrm{FN}, \mathrm{NY}, \mathrm{NN}\} . \varphi T_{i}$ expresses the relative fairness reference point of the collector. $\lambda$ represents the fairness concern coefficient of collectors, and $\lambda \geq 0$. When $\lambda$ becomes bigger, it means that the collectors pay more attention to revenue distributional fairness. When $l \in\{\mathrm{FY}, \mathrm{FN}\}$, there exists $\lambda>0$, which means the collectors are concerned with both their own profit and the revenue distribution fairness. At this time, the aim of the collectors is to achieve utility maximization. When $l \in\{\mathrm{NY}, \mathrm{NN}\}$, there exists $\lambda=0$; the collectors are to pursue profit maximization. Here, $u_{T_{i}}^{l}=\pi_{T_{i}}^{l}$. Based on assumptions, both the manufacturer and the retailer only pursue profit maximization.

4.2. The Model C. Supply chain is effective in the centralized model, where the utility always acts as a comparison benchmark of operational efficiency in different incentive contracts. In this model, all the members co-determine the optimal retailing price and recycling price to achieve the maximal profit. The wholesale price and the transfer price influence is not the variation of the gross profit but the distribution of it among the manufacturer, the retailer, and the collectors. The profit of supply chain $\pi_{\mathrm{sc}}^{C}$ is the following:

$$
\max _{p, A_{i}} \pi_{s c}^{C}=(p-c) D+\sum_{i=1}^{2}\left(\Delta-A_{i}\right) G_{i} .
$$

Proposition 1. Under the model $C$, the optimal pricing decisions of the system are

$$
\begin{aligned}
p^{C *} & =\frac{a+b c}{2 b}, \\
A_{i}^{C *} & =\frac{\Delta(1-\delta)-h}{2(1-\delta)} .
\end{aligned}
$$

By backward induction, we obtain Proposition 1. Proofs of all propositions and corollaries in the paper are provided in the Appendix.

4.3. The Model NN. In the model NN, the manufacturer, the retailer, and the collectors are all independent decisionmakers, who are all fairness-neutral to achieve the maximal self-interest. The manufacturer is the leader, who first sets the wholesale price as well as the transfer price of used products. Then, the retailer sets the retail price. Meanwhile, the collectors set the recycling price. By the backward induction, the optimal pricing decision in the CLSC can be obtained.

Proposition 2. Under the model NN, the optimal pricing decisions of the system are

$$
\begin{aligned}
& w^{\mathrm{NN} *}=\frac{a+b c}{2 b}, \\
& B^{\mathrm{NN} *}=\frac{(1-\delta) \Delta-h}{2(1-\delta)}, \\
& p^{\mathrm{NN} *}=\frac{3 a+b c}{4 b}, \\
& A_{i}^{\mathrm{NN} *}=\frac{(1-\delta) \Delta+h(2 \delta-3)}{2(1-\delta)(2-\delta)} .
\end{aligned}
$$

Corollary $\pi_{s c}^{N N *}<\pi_{s c}^{C *}$. 
Affected by double marginalization, the goal of all the members in CLSC is to maximize their profit, which usually lowers supply chain performance. When setting the transfer price, the manufacturer does not consider the profit of the collectors. The influence of double marginalization causes the collectors to cut down the recycling price, thus decreasing the collection quantity, which leads to the loss of CLSC efficiency. However, because the declining rate of the collecting quantity is not as fast as the demanding quantity, the return rate has increased.

4.4. The Model FY. In the model FY, when the collectors are fairness-concerned, they seek the maximization of the utility. In the meantime, the manufacturer also takes the collectors' fairness concern into account.

Proposition 3. Under the model FY, the optimal pricing decisions of the system are

$$
\begin{aligned}
B^{\mathrm{FY} *} & =\frac{\Delta(1-\delta)(6+9 \lambda-2 \lambda \delta)-h(6+3 \lambda+\lambda \delta)}{12(1-\delta)(1+\lambda)}, \\
A_{i}^{\mathrm{FY} *} & =\frac{\Delta(1-\delta)(6+3 \lambda+2 \lambda \delta)+h[6(2 \delta-3)+\lambda(5 \delta-9)]}{4(1-\delta)[3(2-\delta)+\lambda(3-\delta)]} .
\end{aligned}
$$

Particularly, when $\lambda=0$, the model FY goes back to the model NN.

\section{Corollary 2}

(1) $\partial A_{i}^{F Y *} / \partial \lambda>0, \partial B^{F Y *} / \partial \lambda>0$;

(2) $B^{F Y *}>B^{N N *}, A_{i}^{F Y *}>A_{i}^{N N *}$.

Corollary 2 indicates that (1) when the collectors are fairness-concerned, "reciprocity" is developed between the collector and the manufacturer; namely, the manufacturer who knows the collectors' fairness concern raises the transfer price, and at the same time, the collectors also raise the recycling price to indirectly "reward" the manufacturer. Corollary 2 also suggests that, in the model FY, the more fairness-concerned the collectors are, the more efforts the two parties are willing to pay. (2) Compared with the model $\mathrm{NN}$, in the model FY, due to considering the fairness concern of the collectors, the manufacturer will raise the transfer price to deliver part of the profit to the collectors. After knowing the strategy, the collectors will also put up the recycling price to indirectly "reward" the manufacturer, which is beneficial to increase the collection quantity of the used products so as to achieve the goal of saving resources and protecting the environment.

4.5. The Model FN. In the model FN, when the collectors are fairness-concerned, which is not considered by the manufacturer, the manufacturer makes his own decision based on the reaction function when the collectors are fairnessconcerned.
Proposition 4. Under the model FN, the optimal pricing decisions of the system are

$$
\begin{aligned}
B^{\mathrm{FN} *} & =\frac{(1-\delta) \Delta-h}{2(1-\delta)} \\
A_{i}^{\mathrm{FN} *} & =\frac{\Delta(1-\delta)(3+2 \lambda \delta)-3 h[(3-2 \delta)+\lambda(2-\delta)]}{2(1-\delta)[3(2-\delta)+\lambda(3-\delta)]} .
\end{aligned}
$$

Particularly, when $\lambda=0$, the model FN goes back to the model NN.

Corollary 3. $A_{i}^{F N *}<A_{i}^{F Y *}, B^{F N *}<B^{F Y *}, r_{s c}^{F N *}<r_{s c}^{F Y *}$.

Corollary 3 shows, compared with the case where the collectors' fairness concern is recognized by the manufacturer, in the model FN, when this kind of fairness concern is not recognized, the collectors will passively take action to indirectly "revenge" the manufacturer by lowering recycling price, which is harmful to the development of the CLSC; therefore, the goal of resource saving and environmental protection cannot be achieved.

4.6. The Model NY. In reality, the party in a leadership position who gets most of the profit will do something to care about subordinates; for example, the manufacturer will raise the transfer price to promote the loyalty of the collectors and simultaneously make the collectors pay more collecting efforts, thus improving return rate. It not only meets relevant laws and regulation but also acquires more benefit by reproduction. However, when the collectors are satisfied with current status or have already acknowledged their own efforts and what they get, the collectors will not care about distribution fairness of the manufacturer's profit, which is simplified as the model NY.

When the manufacturer "actively" considers fairness concern of the collectors, the manufacturer will make the decision according to the reaction function when the collectors are fairness-concerned. That is, the manufacturer will make decisions based on the model FY, while the collectors, based on the model NN.

Proposition 5. Under the model NY, the optimal pricing decisions of the system are

$$
\begin{aligned}
B^{\mathrm{NY} *} & =\frac{(1-\delta) \Delta(6+9 \lambda-2 \lambda \delta)-(6+\lambda \delta+3 \lambda) h}{12(1+\lambda)(1-\delta)}, \\
A_{i}^{\mathrm{NY} *} & =\frac{\Delta(1-\delta)(6+9 \lambda-2 \lambda \delta)-h(18+15 \lambda-12 \delta-11 \lambda \delta)}{12(1-\delta)(2-\delta)(1+\lambda)} .
\end{aligned}
$$

Particularly, when $\lambda=0$, the model NY goes back to the model NN. Because of the complexity of expressions, the parameter analyses are placed in numerous analysis section. 


\section{Incentive Contract in the Model FY}

The goal of introducing contracts is to improve the profits of participants. Under the model NN, a large number of studies have shown that a variety of contracts can make supply chain coordination. Under the model FN and the model NY, it is difficult for the manufacturer to know the utility function of the collectors. Therefore, it is difficult for the supply chain leader (manufacturer) to understand the payment function of the contract receiver (collectors), and it is unrealistic to achieve perfect coordination of the supply chain.

This section only discusses the model FY; that is, the collectors are fairness-concerned, and the manufacturer who considers the collectors' fairness concern designs incentive contracts. Here, the Pareto improvement of the CLSC is realized by two-part Tariff contract mechanism. The paper regards the retailer as an independent decisionmaker, so his decisions under incentive contracts will not change.

Assume the contract to the collector $T_{i}$ offered by the manufacturer is $\left(F_{i}, B^{t}\right) . F_{i}$ presents the manufacturer's franchise fees offered by the collector, which helps the manufacturer gain the service by the collector. $B^{t}$ shows transfer price under incentive contracts and the superscript " $t$ " symbolizes the decisions under the contracts, so the decision models of the manufacturer and the collector go as follows:

$$
\begin{aligned}
& \max \pi_{M}^{t}=\left(w^{t}-c\right) D^{t}+\sum_{i=1}^{2}\left(\Delta-B^{t}\right) G_{i}^{t}+F_{1}+F_{2}, \\
& \text { s.t. }\left\{\begin{array}{l}
\pi_{T_{i}}^{t}=\left(B^{t}-A_{i}^{t}\right) G_{i}^{t}-F_{i}, \\
u_{T_{i}}^{t}=\pi_{T_{i}}^{t}+\lambda\left(\pi_{T_{i}}^{t}-\varphi_{T_{i}}^{t}\right) \geq u_{T_{i}}^{\mathrm{FY} *}(\mathrm{IV}), \\
\frac{\partial u_{T_{i}}^{t}=0}{\partial A_{T_{i}}^{t}}=0(\mathrm{IC}), \\
i=1,2 .
\end{array}\right.
\end{aligned}
$$

Proposition 6. Based on the incentive contract proposed by the manufacturer, there exists the only system equilibrium solution in the CLSC, and the manufacturer's optimal transfer price $B t *$ and the collector's optimal collection price $A_{i}^{t *}$ are, respectively, as follows:

$$
\begin{aligned}
B^{t *} & =\frac{\Delta B^{t 1}-3 \delta B^{t 2}+\delta^{2} B^{t 3}+h B^{t 4}}{12(1+\lambda) B^{t 5}}, \\
A_{T_{i}}^{t *} & =\frac{\Delta A_{T_{i}}^{t 1}-h A_{T_{i}}^{t 2}}{4 B^{t 5}} .
\end{aligned}
$$

Among them,

$$
\begin{aligned}
& B^{t 1}=9\left(8+24 \lambda+24 \lambda^{2}+7 \lambda^{3}\right)-2 \delta^{3} \lambda^{2}(3+\lambda), \\
& B^{t 2}=36+104 \lambda+103 \lambda^{2}+28 \lambda^{3}, \\
& B^{t 3}=36+102 \lambda+111 \lambda^{2}+29 \lambda^{3}, \\
& B^{t 4}=\delta^{2} \lambda^{2}(3+\lambda)-9 \lambda(2+\lambda)^{2}-3 \delta\left(12+16 \lambda+9 \lambda^{2}+2 \lambda^{3}\right), \\
& B^{t 5}=6+15 \lambda+6 \lambda^{2}+\delta^{2} \lambda(3+\lambda)-\delta\left(6+17 \lambda+6 \lambda^{2}\right), \\
& A_{T_{i}}^{t 2}=12+12 \lambda(3-\delta)+5 \lambda^{2}(3-\delta), \\
& A_{T_{i}}^{t 1}=3\left(4+8 \lambda+3 \lambda^{2}\right)-2 \delta^{2} \lambda^{2}-\delta\left(12+22 \lambda+5 \lambda^{2}\right) .
\end{aligned}
$$

\section{Numerical Analysis}

In the previous part, the two-part Tariff contract mechanism is established to improve the efficiency of the CLSC. In this section, numerous analyses are applied to verify its efficiency and the influence of fairness concern and competitive intensity between collectors on decisions of the CLSC is studied. Denote the model parameters $a=1000, b=1, h=20$, $c=120, \mathrm{cr}=40$, and $\Delta=80$. By replacing these parameters into the above models, the paper discusses the influence of fairness concern and competitive intensity between the collectors on decisions of the CLSC.

6.1. Impact of Distributional Fairness Concern $\lambda$ on the CLSC. In order to analyze the impact of distributional fairness concern on decisions of the CLSC, it is assumed that the collectors' competitive intensity remains unchanged (let $\delta=0.2$ ). The influence of the collectors' fairness concern on pricing decisions of the CLSC is shown in Figure 1. Figure 2(a) manifests that, under coordination, the collectors' transfer price offered by the manufacturer is higher. Moreover, when the manufacturer does not consider the fairness concern of the collectors, this transfer price is unchanged with the collectors' fairness concern whether in the model NN or FN. But in the model FY or NY, whether the concern of the manufacturer about the collectors is "active" or "passive," the transfer price of the manufacturer will amplify with coefficient of the collector's fairness concern.

Figure 2(b) indicates under the coordination, after getting a higher transfer price, the collectors will also raise recycling price to "repay" the manufacturer. When the collectors' fairness concern does not receive the manufacturer's response, the collectors will rapidly reduce recycling price, which is the lowest this time. Conversely, when the collectors are not fairness-concerned but the manufacturer "proactively" considers the collectors are fairness-concerned, the collectors become more active, willingly accepting a higher recycling price than that obtained in the case where their fairness concern is responded to by the manufacturer, and this price is just lower than that in coordination state.

Figure 2(c) suggests in coordination state, due to the highest recycling price of the collectors and the largest 


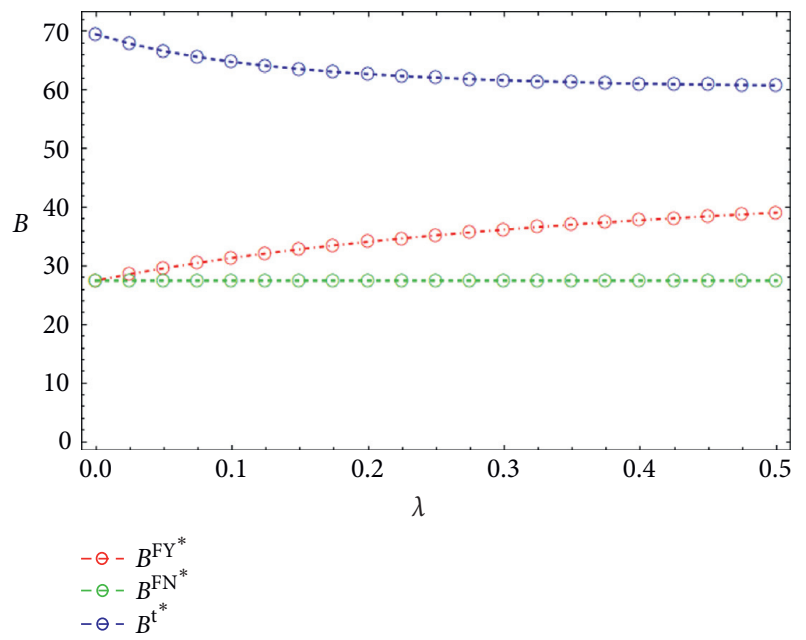

(a)

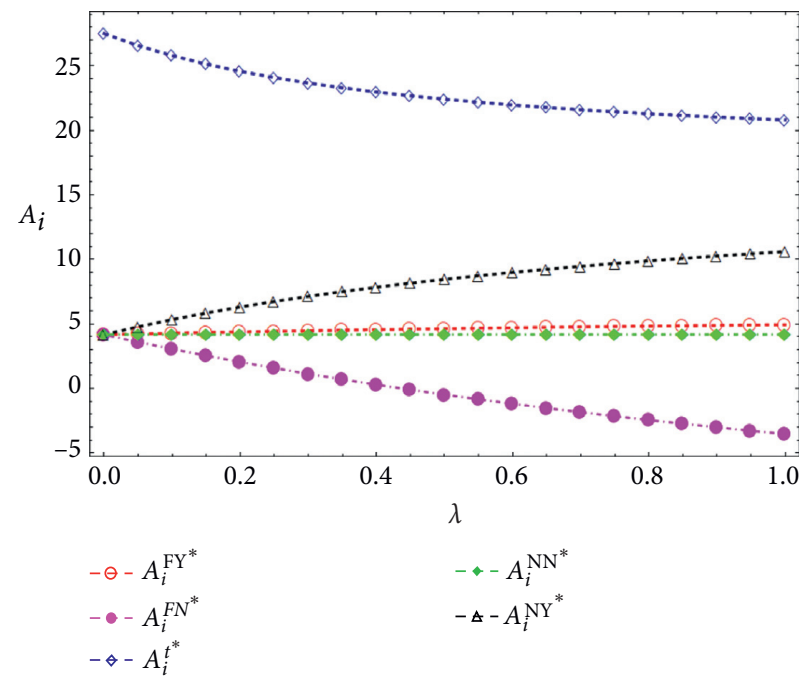

(b)

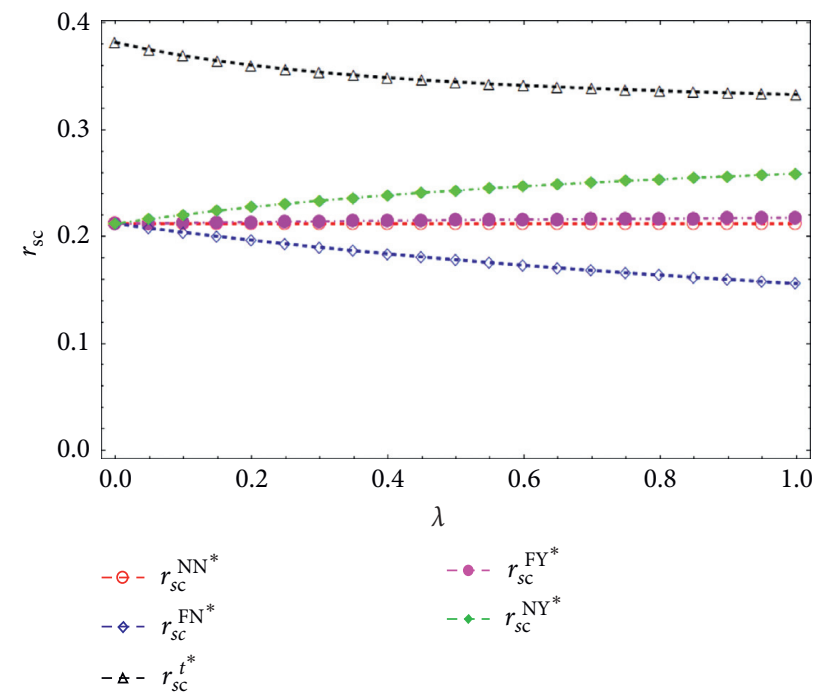

(c)

Figure 2: The impact of fairness concern on decisions of the CLSC. (a) The influence of fairness concern on transfer price. (b) The influence of fairness concern on recycling price. (c) The influence of fairness concern on return rate of the CLSC.

collection quantity and the unchanged retail price of the retailer in all models, the return rate is the most efficient when sales volume is invariant. However, the return rate will decrease as fairness concern increases. In the model FN, the collectors' substantially reducing the recycling price to indirectly "punish" the manufacturer leads to the lowest return rate, which "hurts" the CLSC as well as sustainable development of enterprises and society. This figure also shows, whether the concern of the manufacturer about the collectors is "active" or "passive," the return rate is higher than that when the manufacturer does not concern the collectors' fairness. Clearly, considering the long-term development, whether the collectors are fairness-concerned or not, the fairness concern of the manufacturer about the collectors is the most beneficial to the CLSC members and the environment.
From Figure 3(a), it is known that, in coordinated state, the profit of the manufacturer is the maximum. Because the fairness concern of the collectors will always sacrifice the manufacturer's profit, in the models FY, NY, and FN, only if there is one party who considers the collectors' fairness concern, the loss of the manufacturer's profit is minimal. When the collectors are fairness-concerned but the manufacturer neglects it, the loss is the maximum. From Figure 3(b), it suggests that only when the manufacturer considers the collectors' fairness concern, whether it is "active" or "passive," will the collectors' profit get massively promoted. In particular, the concern is "active"; the profit gets faster growth. In Figure 3(c), when the collectors' fairness concern is not responded to by the manufacturer, the CLSC efficiency is the lowest and decreases faster. When the collectors get "active" attention by the manufacturer, the 

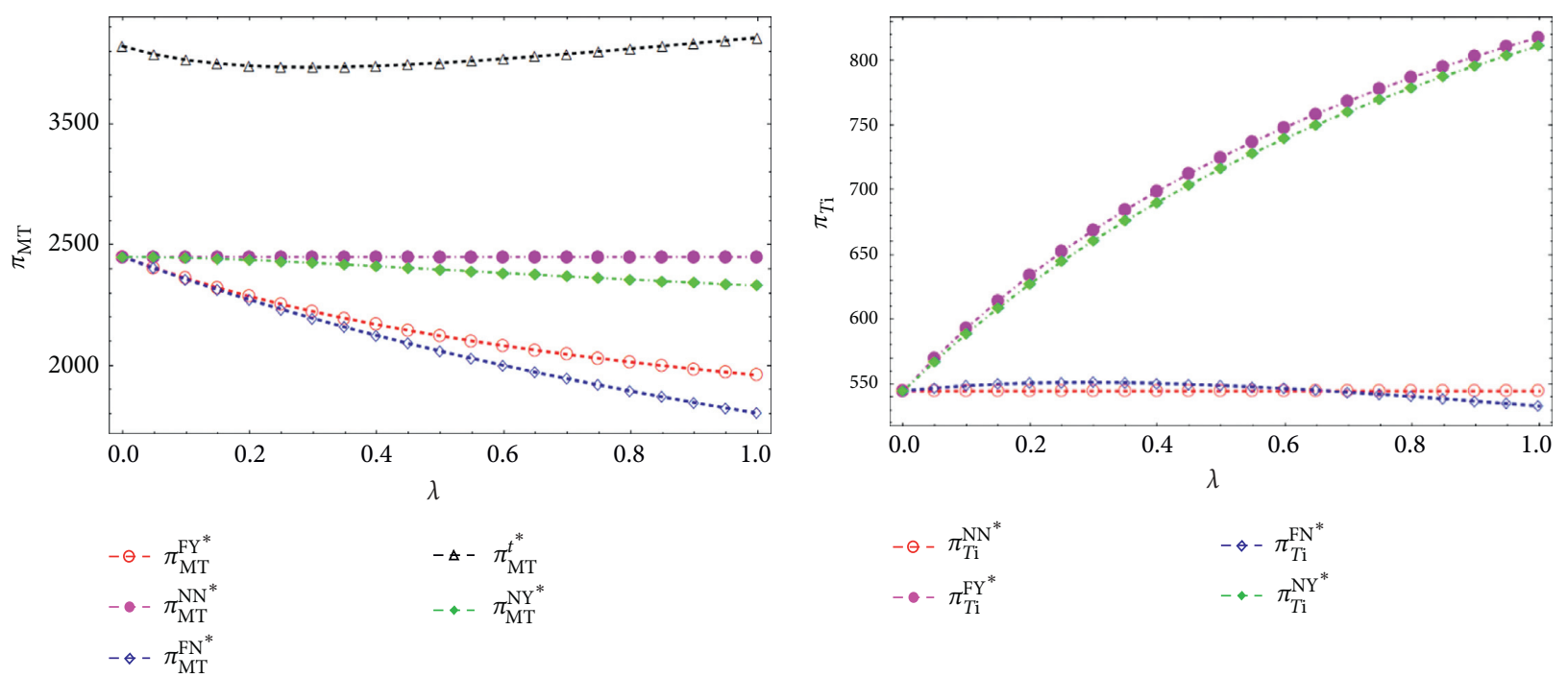

(a)

(b)

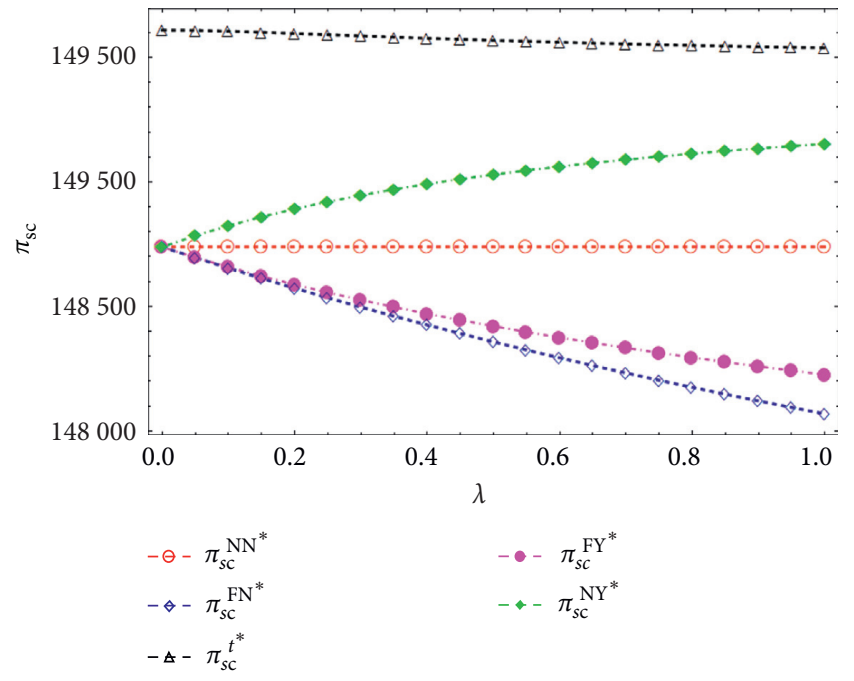

(c)

Figure 3: The influence of fairness concern on profit of the CLSC members. (a) The influence of fairness concern on profit of the manufacturer. (b) The influence of fairness concern on profit of the collectors. (c) The influence of fairness concern on profit of the CLSC.

growth speed of the collectors' profit is faster than decreasing speed of the manufacturer's profit, which increases the profit and performance of the CLSC.

6.2. Impact of Competitive Intensity $\delta$ on the CLSC. To analyze the influence of competitive intensity between collectors on decisions of CLSC, assume the fairness concern coefficient of the collectors remains unchanged $(\lambda=0.4)$. In order to satisfy different parameter conditions, $\delta$ denotes competitive intensity between the collectors which varies from 0 to 0.5 , the range of which changes with the parameter.

From Figure 4, it is known that, no matter what the model is, the manufacturer's transfer price decreases with increase of the competitive intensity. This is because the manufacturer knows the substitution relation between the collectors; he will not worry about the recycling of used products. While the collectors receive the information of the manufacturer's decreased transfer price, out of fairness consideration, the collectors will cut down the recycling price, which leads to the loss of return rate and efficiency of the CLSC. Therefore, as a channel leader, it is indispensable for the manufacturer to take some measures to control the competitive intensity of the collection channel.

6.3. Impact of per Unit of Saving Cost $\Delta$ on the CLSC. As is shown in Figure 5, in various models, the more saving cost in recycling used products the manufacturer has, the more willing he is to pay a higher price for reproduction. Because of the symmetry information, when getting a higher transfer price, the collectors will be more willing to pay a higher recycling price to conduct recycling activities. 

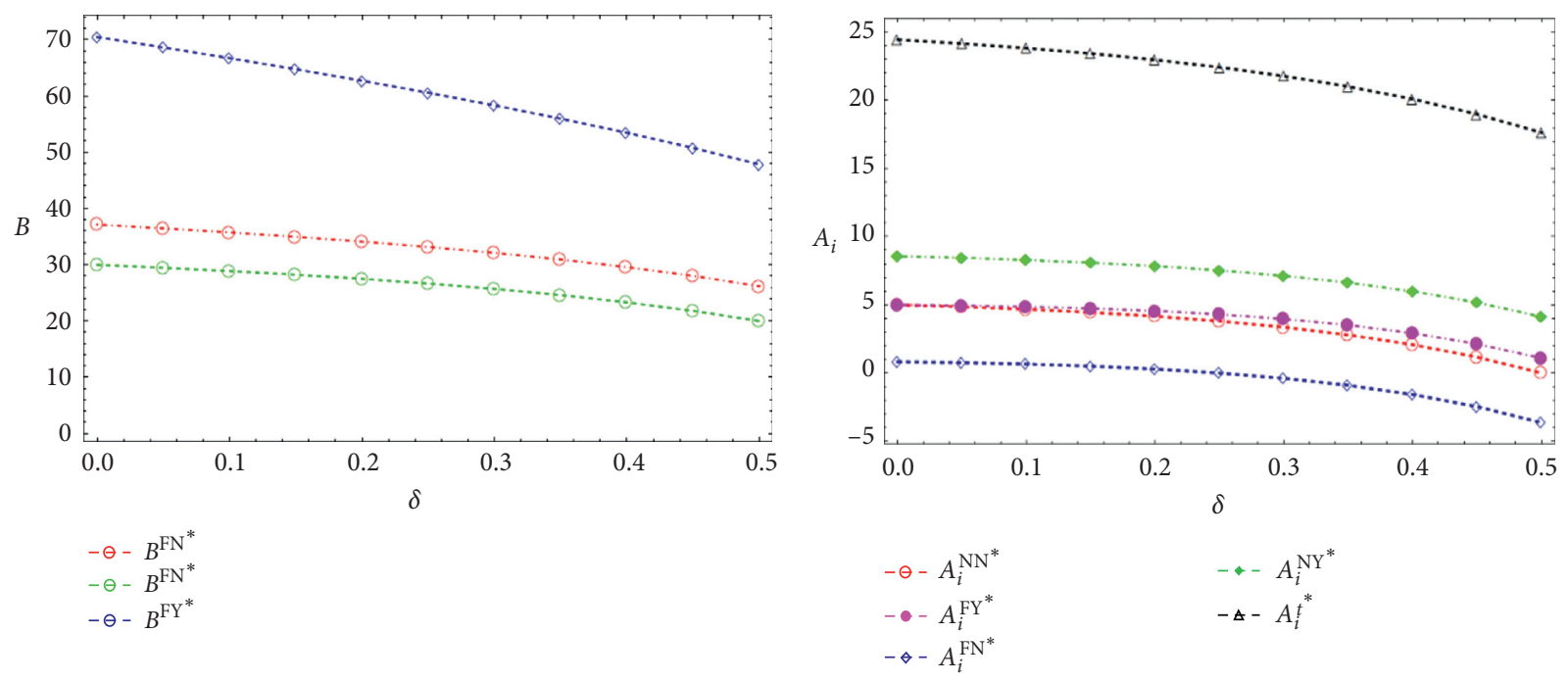

(a)

(b)

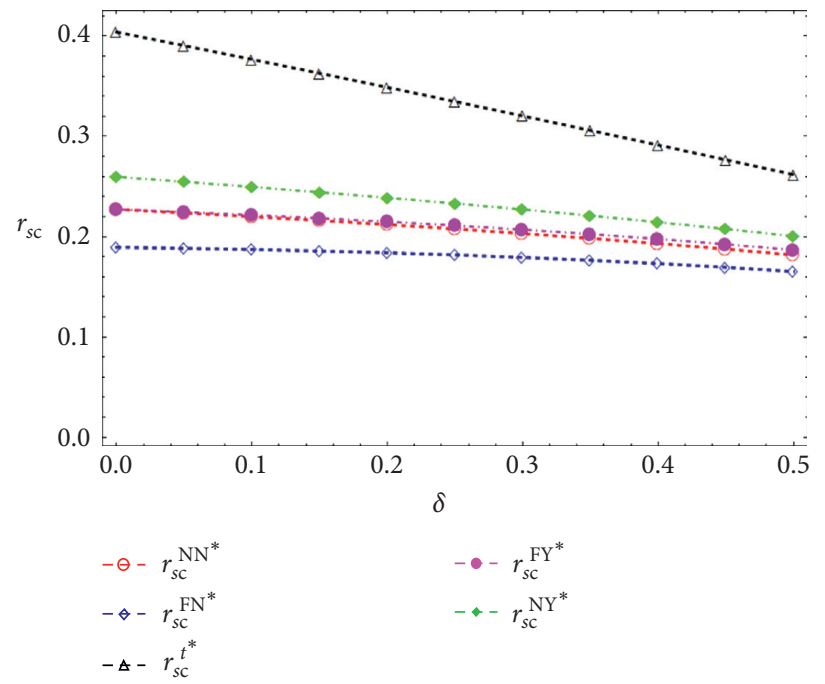

(c)

FIgURE 4: The influence of competitive intensity on decisions of the CLSC (a) The influence of fairness concern on profit of the manufacturer. (b) The influence of competitive intensity on transfer price. (c) The influence of competitive intensity on return rate of the CLSC.

\section{Management Insights, Limitation, and Future Research}

The paper mainly studies the influence of the collectors' fairness concern on the CLSC in the case where the collectors are competitive. The manufacturer, as a leader of the CLSC, who has the advantage of priority decisions, first sets the wholesale price and the transfer price and then the retailer and the collectors decide on the retail price and recycling price recycling price. Through the backward induction method, the equilibrium solutions of the system are generated under five models.

7.1. Management Insights. From the analysis results, some managerial insights can be derived on the pricing decision in the case where the collectors consider fairness concern, as follows.
(1) In the model $\mathrm{NN}$, collectors are unfairness-concerned, and the manufacturer does not consider the collectors' fairness concern. At this point, the manufacturer realizes the maximum profit. It is obvious that, as the leader of the closed-loop supply chain, he gets most of the profits. Naturally, he hopes that the followers not pay too much attention to the distribution of income but also diligently serve him.

(2) In the model NY, the manufacturer "passively active" considers the fairness concern of the collectors and raises transfer price to surrender part of the profit so that the collectors also raise the recycling price to "reward" the manufacturer indirectly. A virtuous circle is formed between the two parties with their mutually beneficial behavior, which has a positive effect on sustainable development of the CLSC. 


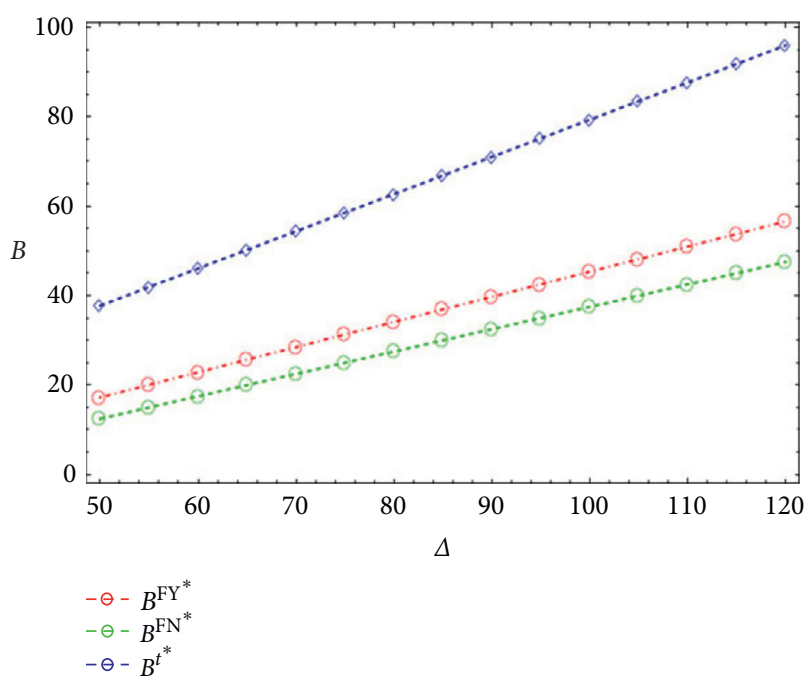

(a)

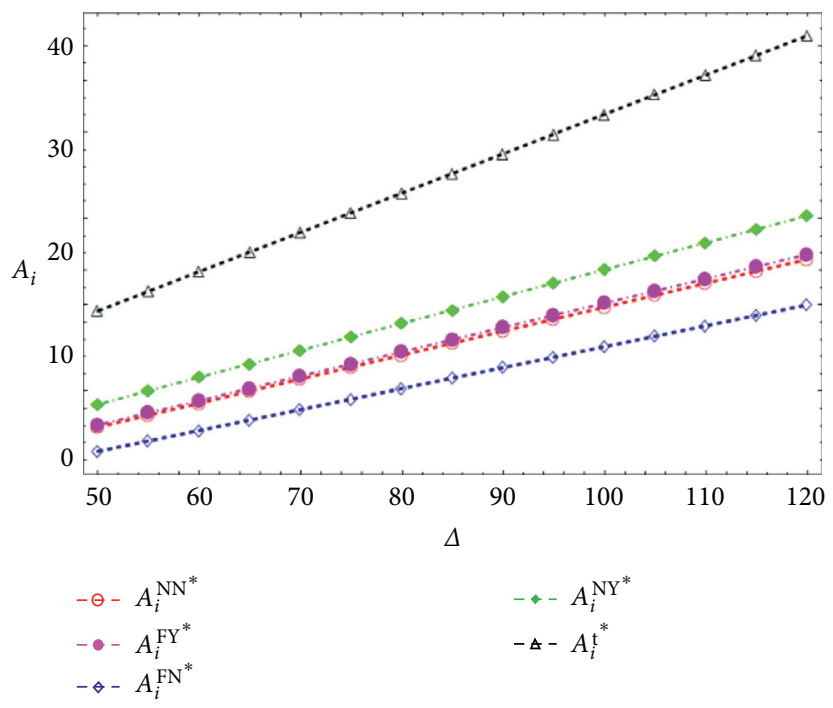

(b)

Figure 5: The influence of per saving cost on decisions of the CLSC. (a) The influence of per saving cost on transfer price. (b) The influence of per unit of saving cost on recycling price.

(3) In the model FN, when the collectors are fairnessconcerned and the manufacturer ignores the collectors' fairness concern, the equilibrium recycling price sets lower for the purpose of achieving more profits by the collector, thus "hurting" both and "harming" the long-term development of the CLSC.

(4) In the model FY, when the collectors are fairnessconcerned and that is considered by the manufacturer, this fairness concern improves the collectors' benefit but "hurts" the manufacturer's. Therefore, the manufacturer is more eager to establish an effective and practical contract to increase the interest. Considering that the collectors are fairness-concerned and the manufacturer takes it into account, a two-part Tariff contract is proposed in this paper. All the theoretical and numerous analyses suggest both of the profits of the manufacturer and the collectors achieve Pareto improvement with the proposed contract.

(5) Fourthly, fierce competition will result in a lower efficiency of the CLSC. As a channel leader, it is necessary for the manufacturer to establish corresponding mechanism to control the competition and maintain a long-term healthy development of the CLSC.

7.2. Limitation and Future Research. Among these four decentralized cases, whether the collectors are fairnessconcerned or the manufacturer pays the collectors' fairness concern will not change the pricing decision of the retailer, which is based on the model assumptions that the fairness concern of the collectors only impacts reverse channel. Therefore, considering the influence of the collectors' efforts and the manufacturer's social responsibility on the decisions of the CLSC, which will affect not only the reverse channel, but also the forward channel, merits further research.

The other limitations of this paper are that we did not consider the retailer's Shapley fair distribution. How about if we think about it? In addition, we did not consider the evolutionary stable strategies of the manufacturers and the collectors.

\section{Appendix}

Proof of Proposition 1. The Hessian matrix of $\pi_{\mathrm{sc}}^{C}$ about $p$ and Ai goes as follows:

$$
H=\left(\begin{array}{cc}
-2 b & 0 \\
0 & -2
\end{array}\right)
$$

From the above formula, it can be inferred that Hessian matrix is negative definite; that is, $\pi_{\mathrm{sc}}^{C}$ about $p$ and $A_{i}$ is a strictly concave function. Hence, there exists the only optimum solution maximizing profits of the CLSC. With the first-order condition, the optimal price decision in the model $\mathrm{C}$ can be obtained.

Proof of Proposition 2

(1) According to

$$
\frac{\partial^{2} \pi_{R}^{\mathrm{NN}}}{\partial p^{2}}=-2 b<0,
$$

it can be inferred that the profit function of the retailer is strictly a concave function, and there exists the only optimal solution $p$ which makes the profit of the retailer maximum. With the first-order condition, we get 


$$
p^{\mathrm{NN} *}=\frac{a+b w^{\mathrm{NN} *}}{2 b}
$$

(2) According to

$$
\frac{\partial^{2} \pi_{T_{i}}}{\partial A_{i}^{2}}=-2<0
$$

it can be inferred that the profit of the collector is strictly a concave function, so there exists the only optimal solution which makes maximum profit of the collector. With the first-order condition, we get

$$
A_{i}^{\mathrm{NN} *}=\frac{B^{\mathrm{NN} *}-h+\delta A_{j}}{2} \text {. }
$$

According to the symmetry of the collectors,

$$
A_{i}^{\mathrm{NN} *}=\frac{B^{\mathrm{NN} *}-h}{2-\delta}
$$

(3) Replacing $p^{\mathrm{NN} *}$ and $A_{i}^{\mathrm{NN} *}$ into the objective function of the manufacturer, we get

$\pi_{M}^{\mathrm{NN}}=\frac{1}{2}(w-c)(a-b w)+\frac{2}{2-\delta}(\Delta-B)(h+B-B \delta)$.

Therefore, the Hessian matrix of the profit function of the manufacturer $\pi_{M}^{\mathrm{NN}}$ about wholesale price $w$ and transfer price $B$ is

$$
H=\left(\begin{array}{cc}
-b & 0 \\
0 & \frac{-4(1-\delta)}{2-\delta}
\end{array}\right) .
$$

From the above expression, Hessian matrix is negative definite. $\pi_{M}^{\mathrm{NN}}$ is a strictly concave function about B and $w$. So there exists the only optimal solution which makes maximum profit of the manufacturer. With the first-order condition, the optimal pricing decision in model $\mathrm{NN}$ is

$$
\begin{aligned}
& w^{\mathrm{NN} *}=\frac{a+b c}{2 b}, \\
& B^{\mathrm{NN} *}=\frac{(1-\delta) \Delta-h}{2(1-\delta)} .
\end{aligned}
$$

Furthermore, the retailer's optimal sailing price and collector's optimal collection price are, respectively, as follows:

$$
\begin{aligned}
p^{\mathrm{NN} *} & =\frac{3 a+b c}{4 b} \\
A_{i}^{\mathrm{NN} *} & =\frac{(1-\delta) \Delta+h(2 \delta-3)}{2(1-\delta)(2-\delta)} .
\end{aligned}
$$

Proof of Corollary 1

$$
\begin{aligned}
A_{i}^{C *}-A_{i}^{\mathrm{NN} *} & =\frac{\Delta(1-\delta)+h}{2(2-\delta)}>0, \\
p^{C *}-p^{\mathrm{NN} *} & =\frac{-a+b c}{4 b}<0, \\
r_{\mathrm{sc}}^{C *}-r_{\mathrm{sc}}^{\mathrm{NN} *} & =\frac{-2 \delta[\Delta(1-\delta)+h]}{(2-\delta)(a-b c)}<0, \\
\pi_{\mathrm{sc}}^{C *}-\pi_{\mathrm{sc}}^{\mathrm{NN} *} & =\frac{(a-b c)^{2}}{16 b}+\frac{[\Delta(1-\delta)+h]^{2}(1-\delta)}{2(2-\delta)^{2}}>0 .
\end{aligned}
$$

Proof of Proposition 3 From,

$$
\frac{\partial^{2} u_{T_{i}}^{\mathrm{FY}}}{\partial\left(A_{i}^{\mathrm{FY}}\right)^{2}}=-(2+\lambda)<0
$$

it can be known that the utility function of the collectors is a strictly concave function about collection price and there exists the only optimal solution $A_{i}^{\mathrm{FY} *}$, making the maximum $u_{T_{i}}^{\mathrm{FY}}$. With the first-order condition, we get

$A_{i}^{\mathrm{FY} *}=\frac{2 \delta(3+\lambda) A_{j}^{F Y}+6(1+\lambda) B^{F Y *}+(6+9 \lambda) h+\lambda \Delta(3-2 \delta)}{6(2+\lambda)}$.

By symmetry, the expression of $A_{i}^{\mathrm{FY} *}$ can be acquired. Substituting $A_{i}^{\mathrm{FY} *}$ into the manufacturer's profit function, $B_{i}^{\mathrm{FY} *}$ can be acquired.

Proof of Corollary 2

(1) $\partial A_{\dot{\mathrm{FY}} *}^{\mathrm{FY}} / \partial \lambda=3 \delta[\Delta(3-2 \delta)+h] / 4[3(2-\delta)+\lambda(3-$ $\delta)]^{2}>0, \partial B_{i}^{\mathrm{FY} *} / \partial \lambda=h(3-\delta)+\left(3-5 \delta+2 \delta^{2}\right) \Delta / 4$ $(1-\delta)(1+\lambda)^{2}>0$.

(2) $B^{\mathrm{FY} *}-B^{\mathrm{NN} *}=\lambda[\Delta(1-\delta)(3-2 \delta)+h(3-\delta)] / 12(1-$ $\delta)(1+\lambda)>0, A_{i}^{\mathrm{FY} *}-A_{i}^{\mathrm{NN} *}=\lambda \delta \quad[\Delta \quad(3-2 \delta)+h] /$ $4(2-\delta)[3(2-\delta)+\lambda(3-\delta)]>0$.

Proof. of Proposition 4. In the model FN, when the collectors are fairness-concerned, which is ignored by the manufacturer, that is, the manufacturer's optimal decision is the same as that in the model NN, we get

$$
B^{\mathrm{FN} *}=\frac{(1-\delta) \Delta-h}{2(1-\delta)} \text {. }
$$

Meanwhile, the collectors will make decisions according to self-utility maximization under fairness concern. We get

$$
A_{i}^{\mathrm{FN} *}=\frac{6(1+\lambda)\left(B^{\mathrm{FN} *}-h\right)+3 \lambda(h-\Delta)+2 \lambda \delta \Delta}{2[3(2-\delta)+\lambda(3-\delta)]} .
$$


By replacing $B^{\mathrm{FN} *}$ into the equation above, the theorem gets proven.

Proof of Corollary 3

$$
\begin{aligned}
A_{i}^{\mathrm{FN} *}-A_{i}^{\mathrm{FY} *} & =\frac{\lambda[\Delta(1-\delta)(2 \delta-3)+h(\delta-3)]}{4(1-\delta)[3(2-\delta)+\lambda(3-\delta)]}<0, \\
B_{i}^{\mathrm{FY} *}-B_{i}^{\mathrm{FN} *} & =\frac{\lambda[\Delta(1-\delta)(3 \delta-2)+h(3-\delta)]}{12(1-\delta)(1+\lambda)}>0, \\
r_{i}^{\mathrm{FY} *}-r_{i}^{\mathrm{FN} *} & =\frac{2 \lambda[\Delta(1-\delta)(3 \delta-2)+h(3-\delta)]}{(a-b c)[3(2+\lambda)+\delta(3+\lambda)]}>0 .
\end{aligned}
$$

Proof of Proposition 5. Because the collectors are fairnessneutral, according to the profit maximization in the model $\mathrm{NN}$, we get

$$
A_{i}^{\mathrm{NY} *}=\frac{B^{\mathrm{NY} *}-h}{2-\delta} .
$$

While considering that the collectors are fairness-concerned, the manufacturer thinks the collector's decision is made according to the model FY, that is,

$$
A_{i}^{\mathrm{NY} *}=\frac{6(1+\lambda)\left(B^{\mathrm{NY} *}-h\right)+3 \lambda(h-\Delta)+2 \lambda \delta \Delta}{2[3(2-\delta)+\lambda(3-\delta)]} .
$$

The collectors make decisions of profit maximization according to the above equation. By replacing the above equation into the objective function of the manufacturer, with the first-order condition, there is

$$
B^{\mathrm{NY} *}=\frac{\Delta(1-\delta)(6+9 \lambda-2 \lambda \delta)-h(6+3 \lambda+\lambda \delta)}{12(1-\delta)(1+\lambda)} .
$$

By replacing $B^{N Y}$ into $A_{i}^{\mathrm{NY} *}$, the theorem gets proven.

Proof of Proposition 6. By backward induction, according to the collector's individual rationality constraint (IR) and incentive constraint (IC), we get $A_{T_{i}}^{t}$ and Fi. By replacing them into the objective function of the manufacturer, the optimal transfer price and the collection price can be obtained.

\section{Data Availability}

The data used to support the findings of this study are included within the article. Since the data used in this study are all used to verify the conclusions obtained in the paper under certain system conditions and are set for complex expressions that cannot obtain analytical solutions, different data can be set in different research environments. The implementation scripts in the form of some mathematics files are available from the authors upon request.

\section{Conflicts of Interest}

The authors declare no conflicts of interest.

\section{Authors' Contributions}

Y.S. and Y.D. contributed to writing; Y.S. and Z.M. provided the case and idea; Y.D. and Z.M. provided revised advice.

\section{Acknowledgments}

The authors gratefully acknowledge the support of National Natural Science Foundation of China (Nos. 71103149, 61472093, and 71761005); Humanities and Social Sciences Foundation of Ministry of Education of China (No. 16YJA630005); Major Project of Philosophy and Social Science Research of Sichuan Province (No. SC17A030); Soft Science Research Project of Chengdu City (No. 2016-RK0000266-ZF); and Academic Project of Guizhou University of Finance and Economics (No. [2017]573 6-024).

\section{References}

[1] "European Policy instruments," 2016, https://www.eea. europa.eu/themes/policy/intro.

[2] “Japanese environmental laws," 2007, http://www.env.go.jp/ en/laws.

[3] "Updated informative digest," 2018, http://www.arb.ca.gov/ regact/levii01/uid.pdf.

[4] V. Smith and G. Keoleian, "The value of remanufactured engines: life-cycle environmental and economic perspectives," Journal of Industrial Ecology, vol. 8, no. 1, pp. 193-221, 2004.

[5] A. Atasu, L. N. Van Wassenhove, and M. Sarvary, "Efficient take-back legislation," Production and Operations Management, vol. 18, no. 3, p. 243, 2009.

[6] H. S. Heese, K. Cattani, G. Ferrer, W. Gilland, and A. V. Roth, "Competitive advantage through take-back of used products," European Journal of Operational Research, vol. 164, no. 1, p. 143, 2005.

[7] R. C. Savaskan, S. Bhattacharya, and L. N. Van Wassenhove, "Closed-loop supply chain models with product remanufacturing," Management Science, vol. 50, no. 2, p. 239, 2004.

[8] M. Huang, M. Song, L. H. Lee, and W. K. Ching, "Analysis for strategy of closed-loop supply chain with dual recycling channel," International Journal of Production Economics, vol. 144, no. 2, p. 510, 2013.

[9] J. Xiao and Z. Huang, "A stochastic differential game in the closed-loop supply chain with third-party collecting and fairness concerns," Sustainability, vol. 11, no. 8, p. 2241, 2019.

[10] L. K. Scheer, N. Kumar, and J.-B. E. M. Steenkamp, "Reactions to perceived inequity in U.S. and Dutch interorganizational relationships," Academy of Management Journal, vol. 46, no. 3, p. 303, 2003.

[11] T. Cui, J. Raju, and Z. Zhang, "Fairness and channel coordination," Management Science, vol. 53, no. 8, pp. 1303-1314, 2007.

[12] X. Pu, L. Gong, and G. Han, "A feasible incentive contract between a manufacturer and his fairness-sensitive retailer engaged in strategic marketing efforts," Journal of Intelligent Manufacturing, vol. 30, pp. 193-206, 2019.

[13] J. Chen, Y.-W. Zhou, and Y. Zhong, "A pricing/ordering model for a dyadic supply chain with buyback guarantee financing and fairness concerns," International Journal of Production Research, vol. 55, no. 18, p. 5287, 2017.

[14] B. Du, Q. Liu, and G. Li, "Coordinating leader-follower supply chain with sustainable green technology innovation on their fairness concerns," International Journal of Environmental Research and Public Health, vol. 14, no. 11, p. 1357, 2017. 
[15] Y. Shu, Y. Dai, and Z. Ma, "Pricing decisions in closed-loop supply chains with peer-induced fairness concerns," Sustainability, vol. 11, no. 18, p. 5071, 2019.

[16] J. Heydari, T.-M. Choi, and S. Radkhah, "Pareto improving supply chain coordination under a money-back guarantee service program," Service Science, vol. 9, no. 2, p. 91, 2017.

[17] J. Heydari, K. Govindan, and A. Aslani, "Pricing and greening decisions in a three-tier dual channel supply chain," International Journal of Production Economics, vol. 217, p. 185, 2019.

[18] M. Esmaeili, G. Allameh, and T. Tajvidi, "Using game theory for analysing pricing models in closed-loop supply chain from short- and long-term perspectives," International Journal of Production Research, vol. 54, no. 7, pp. 2152-2169, 2016.

[19] P. Ma, K. W. Li, and Z.-J. Wang, "Pricing decisions in closedloop supply chains with marketing effort and fairness concerns," International Journal of Production Research, vol. 55, no. 22, p. 6710, 2017.

[20] A. Diabat and A. Jebali, "Multi-product and multi-period closed loop supply chain network design under take-back legislation," International Journal of Production Economics, vol. 231, p. 107879, 2021.

[21] D. Wen, T. Xiao, and M. Dastani, "Pricing and collection rate decisions in a closed-loop supply chain considering consumers' environmental responsibility," Journal of Cleaner Production, vol. 262, p. 121272, 2020.

[22] H. Jalali, A. H. Ansaripoor, and P. De Giovanni, "Closed-loop supply chains with complementary products," International Journal of Production Economics, vol. 229, p. 107757, 2020.

[23] L. Meng, Q. Qiang, Z. Huang, B. Zhang, and Y. Yang, "Optimal pricing strategy and government consumption subsidy policy in closed-loop supply chain with third-party remanufacturer," Sustainability, vol. 12, no. 6, p. 2411, 2020.

[24] N. Wang, Q. He, and B. Jiang, "Hybrid closed-loop supply chains with competition in recycling and product markets," International Journal of Production Economics, vol. 217, pp. 246-258, 2019.

[25] B. C. Giri and S. Sharma, "Manufacturer's pricing strategy in a two-level supply chain with competing retailers and advertising cost dependent demand," Economic Modelling, vol. 38, no. 1, p. 102, 2014.

[26] R. C. Savaskan and L. N. Van Wassenhove, "Reverse channel design: the case of competing retailers," Management Science, vol. 52, no. 1, p. 1, 2006.

[27] M. Ferguson and L. Toktay, "The effect of competition on recovery strategies," Production and Operations Management, vol. 15, no. 3, pp. 351-368, 2006.

[28] D. Lee and S. Sana, "Pricing decisions in a competitive closedloop supply chain with duopolistic recyclers," Mathematical Problems in Engineering, vol. 2020, Article ID 5750370, 22 pages, 2020.

[29] E. Xing, C. Shi, J. Zhang, S. Cheng, J. Lin, and S. Ni, “Double third-party recycling closed-loop supply chain decision under the perspective of carbon trading," Journal of Cleaner Production, vol. 259, p. 120651, 2020.

[30] T.-H. Ho and J. Zhang, "Designing pricing contracts for boundedly rational customers: does the framing of the fixed fee matter?" Management Science, vol. 54, no. 4, pp. 686-700, 2008.

[31] L. Zhang, B. Xue, and X. Liu, "Carbon emission reduction with regard to retailer's fairness concern and subsidies," Sustainability, vol. 10, no. 4, p. 1209, 2018.

[32] Q. Li, T. Xiao, and Y. Qiu, "Price and carbon emission reduction decisions and revenue-sharing contract considering fairness concerns," Journal of Cleaner Production, vol. 190, pp. 303-314, 2018.

[33] Z. Huang, "Stochastic differential game in the closed-loop supply chain with fairness concern retailer," Sustainability, vol. 12 , no. 8 , p. $3289,2020$.

[34] H. Zhang, Z. Zhang, X. Pu, and Y. Li, "Green manufacturing strategy considering retailers' fairness concerns," Sustainability, vol. 11, no. 17, p. 4646, 2019.

[35] B. Li, P. Hou, and Q. Li, "Cooperative advertising in a dualchannel supply chain with a fairness concern of the manufacturer," IMA Journal of Management Mathematics, vol. 28, no. 2, pp. 259-277, 2017.

[36] X. Zhen, D. Shi, S. Tsai, and W. Wang, "Pricing decisions of a supply chain with multichannel retailer under fairness concerns," Mathematical Problems in Engineering, vol. 2019, Article ID 9547302, 22 pages, 2019.

[37] Y. Shu, Y. Dai, and Z. Ma, "Pricing decisions in closed-loop supply chains with multiple fairness-concerned collectors," IEEE Access, vol. 8, pp. 151335-151349, 2019.

[38] L. Petrosjan and G. Zaccour, "Time-consistent Shapley value allocation of pollution cost reduction," Journal of Economic Dynamics and Control, vol. 27, no. 3, pp. 381-398, 2003.

[39] C. Ozgun, Y. Chen, and J. Li, "Chanel coordination under fairness concerns and nonlinear demand," European Journal of Operational Research, vol. 207, no. 3, pp. 1321-1326, 2010.

[40] S. Du, T. Nie, C. Chu, and Y. Yu, "Reciprocal supply chain with intention," European Journal of Operational Research, vol. 239, no. 2, pp. 389-402, 2014.

[41] E. Katok and V. Pavlov, "Fairness in supply chain contracts: a laboratory study," Journal of Operations Management, vol. 31, no. 3, pp. 129-137, 2013.

[42] A. Karakostas, A. Sonntag, and D. J. Zizzo, "Contract choice: efficiency and fairness in revenue-sharing contracts," The Scandinavian Journal of Economics, vol. 119, no. 4, pp. 962-986, 2017.

[43] J. Heydari, K. Govindan, and R. Sadeghi, "Reverse supply chain coordination under stochastic remanufacturing capacity," International Journal of Production Economics, vol. 202, pp. 1-11, 2018.

[44] C. Mondal and B. C. Giri, "Pricing and used product collection strategies in a two-period closed-loop supply chain under greening level and effort dependent demand," Journal of Cleaner Production, vol. 265, p. 121335, 2020.

[45] X. Li, X. Cui, Y. Li, D. Xu, and F. Xu, "Optimisation of reverse supply chain with used-product collection effort under collector's fairness concerns," International Journal of Production Research, 2019.

[46] Z. Zhang and M. Ren, "Closed-loop supply chain coordination strategy for the remanufacture of patented products under competitive demand," Applied Mathematical Modelling, vol. 40, no. 13-14, pp. 6243-6255, 2016.

[47] N. Wang, Y. Song, Q. He, and T. Jia, "Competitive dualcollecting regarding consumer behavior and coordination in closed-loop supply chain," Computers \& Industrial Engineering, vol. 144, p. 106481, 2020.

[48] X.-X. Zheng, Z. Liu, K. W. Li, J. Huang, and J. Chen, "Cooperative game approaches to coordinating a three-echelon closed-loop supply chain with fairness concerns," International Journal of Production Economics, vol. 212, p. 92, 2019.

[49] X.-X. Zheng, D.-F. Li, Z. Liu, F. Jia, and J.-B. Sheu, "Coordinating a closed-loop supply chain with fairness concerns through variable-weighted Shapley values," Transportation Research Part E: Logistics and Transportation Review, vol. 126, pp. 227-253, 2019. 